\title{
Transformer Substation Life Cycle Prediction
}

\author{
Yingjie Zhang ${ }^{1}$, Erkui Chen ${ }^{1}$, Zhen $\mathrm{Li}^{2}$, Pingjie Guo ${ }^{2}$, Xiaoping Liang ${ }^{3}$ \\ ${ }^{1}$ Shan Dong University of Science and Technology, Qingdao 266500, China; \\ ${ }^{2}$ State Grid Wucheng Power Supply Company, Dezhou 253300, China; \\ ${ }^{3}$ State Grid Weifang Power Supply Company, Weifang 261000, China.
}

374946732@qq.com

\begin{abstract}
With the rapid development of the national economy, the pace of construction of power facilities is being continuously accelerated. While carrying out the social responsibility, the electric power enterprises are also pursuing economic, social environment and comprehensive value maximization. Therefore, the current project cost management model of the whole process of power industry in China has been unable to meet the goal of maximizing the efficiency of power enterprises. The life cycle cost (LCC) management is based on the life cycle of the project item as the research object, to implement the control of cost in different stages of project decision, design, construction, operation and maintenance. It is a management method with the minimum in the whole life cycle cost as the target. The research discusses the life cycle cost of substation, and from economic load rate, capacity, number choice and estimation model of whole life cycle of the main transformer economy, analyzes the application of life cycle cost in the choice of main transformer. And then, taking a substation as an example, the example analysis is carried on.
\end{abstract}

Keywords: Transformer, Life Cycle, electric power

\section{INTRODUCTION}

In recent years, with the rapid development of the national economy, the state has accelerated the construction of power facilities. Life cycle cost management takes the project whole life cycle as the research object, and implements the control of cost in various phases: project decision, design, construction, operation and maintenance, which is a management method with the minimum life cycle cost as the objective. The whole life cycle cost management has three characteristics: whole system, full cost and whole process. The application and research of life cycle theory in the substation project has been paid more and more attention to. The research content involves substation engineering scheme decision, project bidding, project construction management, equipment operation and maintenance management, financial management and other fields. In the substation management, the use of theory of full life cycle can effectively manage the project of substation, so as to promote the development of electric power technology to a great extent.

\section{APPLICATION OF FULL LIFE CYCLE IN SELECTION OF MAIN TRANSFORMER}

The main transformer optimization design based on the life cycle cost theory includes two aspects: determination of the economic load rate of the main transformer; selection and prediction of capacity and number of main transformer. Correctly select transformer number and capacity, adopt economical and rational operation mode, safely produce, decrease power consumption and reduce equipment investment are issues of great concern to electric power enterprises. 


\section{Main transformer economic responsibility rate}

The main transformer load rate is always changing in the whole operation process from production until the final operation exit, and it generally shows the role of increasing from small to great. While the whole life unit cost trend is showing a change from big to small and then change from small to big.

(1) Economic load rate of main transformer $\mathrm{P}_{\mathrm{Q}}$

Active power loss of main transformer:

$$
\Delta P=P_{0}+\rho^{2} P_{\mathrm{k}}
$$

Reactive power loss of main transformer:

$$
\Delta Q=Q_{0}+\rho^{2} Q_{\mathrm{k}}
$$

In the above formula, $P_{0}$ refers to no-load loss of main transformer; $P_{k}$ indicates load loss of main transformer; $\rho$ suggests load rate of main transformer; $Q_{0}=I \% \times S$ means no-load loss; and $Q_{k}=U_{k} \% \times S$ indicates reactive load loss.

Main transformer efficiency:

$$
\eta(\rho)=\frac{P_{1}}{P_{2}}=\frac{\rho S \cos \psi T_{\max }}{\rho S \cos \psi T_{\max }+P_{0} T+\rho^{2} p_{k} \tau_{\max }+k_{Q}\left(\mathrm{Q}_{0}+\rho^{2} Q_{k} \tau_{\max }\right)}
$$

In the above formula, $\mathrm{P}_{1}$ means output power of main transformer; $\mathrm{P}_{2}$ indicates load power of main transformer; $\mathrm{S}$ suggests rated capacity of main transformer; $\cos \psi$ represents load power factor; $T_{\max }$ refers to the hours used by the maximum load; $\tau_{\max }$ is annual loss hours; and $\mathrm{K}_{\mathrm{Q}}$ means reactive economic equivalent. Calculating the extremum of above formula, we can get economic load rate:

$$
\rho_{Q}=\sqrt{\frac{P_{0} T+k_{Q} Q_{0} T}{P_{k} \tau \max +k_{Q} Q_{k} \tau_{\max }}}
$$

In (4), the meaning of reactive economic equivalent $K_{Q}$ is to convert the reactive power to the coefficient with active loss at the cost of the economy. In the actual calculation, reactive economic equivalent $K_{Q}$ can be simply recorded as the ratio of reactive power price to active power price. At present, reactive power price and active power price are $0.1 \mathrm{yuan} / \mathrm{kW} \cdot \mathrm{h}$ and $0.65 \mathrm{yuan} / \mathrm{kW} \cdot \mathrm{h}$, respectively, and reactive economic equivalent is 0.154 .

(2) Load rate $\rho_{Q}$ considering the life cycle cost

The final purpose of obtaining economic load rate is to make the life cycle cost of the main transformer the minimum. On the basis of the formula (3), considering the main transformer cost recovery, the main transformer costs each year are included, and the efficiency formula is:

$$
\eta(\rho)=\frac{\rho S \cos \psi T_{\text {max }}}{\rho S \cos \psi T_{\text {max }}+P_{0} T+\rho^{2} p_{k} \tau_{\text {max }}+k_{Q}\left(\mathrm{Q}_{0} T+\rho^{2} Q_{k} \tau_{\max }\right)+k_{\mathrm{C}} \mathrm{C}_{\mathrm{A}}}
$$

In (5), $C_{A}$ means net annual cost of main transformer; $K_{C}$ represents cost equivalent annual economic equivalent of main transformer. Calculating the extremum of above formula, we can get the economic load rate with consideration of cost recovery:

$$
\rho_{Q}=\sqrt{\frac{P_{0} T+k_{Q} Q_{0} T+k_{C} C_{A}}{P_{k} \tau \max +k_{Q} Q_{k} \tau_{\max }}}
$$

From (6), it is seen that, when the net annual cost $\mathrm{C}_{\mathrm{A}}$ of main transformer is great, the economic load rate $\rho_{Q}$ is higher, and even appears that $\rho_{Q}$ larger than 1 (Wei, 2010). At this time, the safe operation of main transformer should be taken as the restraint condition, to choose the upper limit of the safe operating load rate as the economic load rate. 
In general, for substations installed with several transformers with the same capacity, when a main transformer is cut off due to faults, the load rate of the remaining transformers is no more than $130 \%$. As a result, the load rate of each transformer should be:

$$
\rho_{\mathrm{s}}=\rho_{\mathrm{k}} \times N /(\mathrm{N}-1)
$$

In (7), $\rho_{\mathrm{s}}$ indicates the safe operation load rate; $\rho_{k}$ means short-time permissible overload rate. When $\mathrm{N}=2$, $\rho_{\mathrm{s}}=65 \%$; when N=3, $\rho_{\mathrm{s}}=87 \%$; when $\mathrm{N}=4, \rho_{\mathrm{s}} \approx 100 \%$.

\section{Selection and prediction of capacity and number of main transformers}

Although the loss of large capacity main transformer is low and the cost of unit capacity is low, the requirements of ancillary equipment are also high, and the cost of saving may be difficult to compensate for the increase in investment costs.

Select the reasonable main transformer capacity and numbers design scheme, the load rate is controlled in a certain range of economic load rate.

\section{Life cycle estimation model of main transformer}

In accordance with the operating rules of the equipment life cycle, the standard operation state and key control points are regarded as the focus of the whole process of management. On the basis of the theory of life cycle cost and according to the related cost of substation equipment expenditures, the transformer life cycle cost model is constructed. That is:

$$
L C C=I C+O C+M C+F C+D C
$$

In (8), LCC—— Total cost of transformer equipment in the whole life cycle.

IC- Initial input costs, including equipment purchase fees, installation fees, land acquisition fees and so on.

OC_— Operating costs, mainly including equipment energy consumption, cost, status, inspection costs and labor costs.

MC_-Maintenance and repair cost, including daily equipment maintenance cost, planned maintenance cost and personnel training expense, etc (Hinow and Mevissen, 2011).

FC_— Failure cost, including power failure loss, maintenance cost and penalty cost, etc..

DC_-Equipment scrap handling costs, including equipment retirement, processing fees and equipment residual value.

Total life cycle cost components analysis of main transformer:

\section{1) investment cost IC analysis}

IC = equipment purchase fee + installation project fee + land requisition fee + other expenses.

(1) purchase fee

Purchase fee $=$ equipment fee + special tools and initial spare parts fee + on-site service charge + supplier transportation fee.

(2) installation cost

Installation cost $=$ transport cost + construction and installation fee + commissioning fee.

(3) land acquisition fees

Land acquisition fee $=$ gross floor area of the main transformer system * land price.

(4) other expenses. Other costs include training costs, acceptance fees, and the use of expendable tools.

2) operation cost analysis

The operating cost is mainly variable cost of substation project items, which mainly includes three aspects: operation cost, maintenance cost and failure cost (Wong, et al., 2015).

operation cost OC

$\mathrm{N}$ years' equipment cost $=$ transformer equipment body consumption fee + auxiliary equipment consumption fee $=$ no-load loss value $*$ annual operating hours $*$ cost electricity price + (load loss + auxiliary equipment power) $*$ operating hours * load rate * cost power price.

$\mathrm{N}$ years' $\mathrm{OC}=$ daily inspection fee $+\mathrm{n}$ years' equipment cost $=$ annual inspection labor costs $+\mathrm{n}$ years' equipment consumption fee. 
Convert the OC of the $\mathrm{n}$ year to the present value of the base year, and accumulates the OC for each year to obtain operating costs in the life cycle.

(2) maintenance cost MC

MC= periodic overhaul costs + all kinds of periodic maintenance costs

i) periodic overhaul costs. Periodic overhaul cost $=$ supplier equipment and materials costs + supplier service fee + owner equipment, materials, and tools costs + owner labor costs and other expenses of owner.

ii) periodic maintenance cost

Periodic maintenance cost $=$ supplier equipment and materials costs + supplier service fee + owner equipment, materials, and tools costs + owner labor costs and other expenses of owner.

$$
M C=M C a\left[\frac{1}{(1+\lambda)^{T}}+\frac{1}{(1+\lambda)^{2 T}}+\cdots+\frac{1}{(1+\lambda)^{n T}}\right]
$$

In the above formula, MCa refers to the overhaul cost in unit intervals; $\mathrm{T}$ means overhaul cycle; $\mathrm{n}$ indicates the planned maintenance times in per unit interval during the life cycle.

Add the above data to obtain the maintenance and maintenance costs of each year, and then convert to the present value of the base year, and accumulate the MC of each year, then we can get the maintenance cost in the whole life cycle.

(3) failure cost FC

$\mathrm{FC}=$ breakdown cost + failure cost

i )breakdown costs

Annual breakdown cost $=$ annual failure probability $*$ site failure repair fee $=$ annual failure probability $*$ [equipment and material cost + labor cost]

Annual failure probability = annual failure times / statistical year table [times / (year)]

ii ) failure cost

Annual failure cost $=$ annual failure probability * (outage loss cost + grid support electricity cost $)$

$=$ annual failure probability * (outage loss load $*$ outage time + grid support electricity cost) $*$ power supply price

Power loss load, power grid support power and outage time are obtained according to the operation experience of power grid. The price of power supply is determined by the annual actual power supply price of each power company.

The calculation model is:

$$
F C=P \cdot T \cdot \mathrm{a}+R C \cdot M T T R \cdot \lambda
$$

In (10), $\mathrm{P}$ refers to the equipment fault interrupt and power supply power; $\mathrm{T}$ indicates the equipment fault interrupt and power supply time; a suggests the value of users average interrupt power supply; RC means the average cost of repairing equipment failure; MTTR is the average time to repair equipment; $\lambda$ represents annual average failure number (Liu, 2015); $P \cdot T \cdot$ a shows the power penalty cost; and $R C \cdot M T T R \cdot \lambda$ is the cost of repair.

The annual FC is converted to the present value of the base year, and the FC of each year is accumulated, then the failure cost in the whole life cycle can be obtained.

\section{3) disposal cost of decommissioning}

DC analysis: DC= equipment decommissioning processing fee - equipment salvage value

(1) equipment decommissioning fee

Equipment decommissioning fee $=$ cleaning fee $*$ installation cost

(2) salvage value when the equipment is retired

For the equipment reaching the end of service life, its residual value is calculated according to $3 \%$ of the original value; for the equipment not reaching the service life, according to the equipment processing value equal to the original value minus the amount of the annual depreciation of equipment, equipment depreciation rate of $\mathrm{d}$, the fixed rate method calculation is:

$$
d=1-T \sqrt{\frac{K_{I}}{K_{0}}}
$$

In (11), $T$ refers to the depreciation period of the equipment; $K_{0}$ is the original value of the equipment; $K_{L}$ represents the residual value of the equipment at the end of T (Suo, et al., 2017). 
When each value is substituted, the value of $d$ can be calculated, and then the processing value of the equipment in the n-th year is:

$$
K_{L}=K_{0}(1-d)^{n}
$$

The DC model for decommissioning disposal costs is:

$$
D C=\sum_{i=0}^{n} \frac{3 \% K_{0 i}}{(1+\lambda)^{T-T_{0}}}+\sum_{j=0}^{m} \frac{K_{I j}}{(1+\lambda)^{30}}
$$

In (13), $T_{0}$ refers to the initial year of service life calculation; $T^{\prime}$ suggests the equipment purchased year.

\section{Example analysis}

A substation designer applies full life cycle cost analysis method to choose the main transformer. After the primary choice, equipment provided by two transformer manufacturers are recorded as equipment $\mathrm{A}$ and equipment $\mathrm{B}$, and the parameters are shown in table 1 .

TABLE 1. Transformer parameter comparison table

\begin{tabular}{ccc}
\hline Equipment & Equipment A & Equipment B \\
\hline Capacity & $180 \mathrm{MVA}$ & $180 \mathrm{MVA}$ \\
Price & 1322 & 1282 \\
No-load loss $(\mathrm{kW})$ & 95.9 & 100.8 \\
Load loss $(\mathrm{kW})$ & 433.0 & 442.0 \\
Unplanned outage time (h / & 0.56 & 0.71 \\
year) & & \\
Maintenance instructions & The two major overhaul will be carried & Three major overhauls will be carried \\
& out within 30 years, 10 years and 25 & out within 30 years, namely, 5, 15 and \\
& years after commissioning. & 25 years after commissioning. \\
\hline
\end{tabular}

(1) operation cost OC

$$
O C=\left(\Delta p_{0}+\Delta p \rho^{2}\right) T_{0} C_{0}
$$

In (14), $\Delta p_{0}$ means that the no-load of transformer is active power loss, and $\Delta p$ indicates transformer load active loss; $\rho$ suggests transformer load factor, calculated according to $50 \%$ load; $T_{0}$ is annual operating hours of transformers, taking $8760 \mathrm{~h} ; C_{0}$ is unit power price, taking 0.5 yuan / $\mathrm{kWh}$.

(2) maintenance cost MC analysis

The equipment A needs 2 major overhauls in the life cycle, namely in the tenth and twenty-fifth years after the operation; the equipment B needs 3 major repairs, namely in the fifth, tenth and twenty-fifth years after the commissioning. According to the calculation and price of crane design institute, leasing companies and power grid construction company, we make a comprehensive decision-making (Zhang and Wang, 2016). The cost for an overhaul is about 1.478 million yuan, the total cost of equipment $\mathrm{A}$ is 2.956 million yuan, and the total investment of equipment B is 4.434 million yuan. For other minor repairs and pre experimental costs, two manufacturers require the same.

(3) failure cost FC analysis

Unscheduled outage time of equipment $A$ is $0.56 \mathrm{~h} /$ year, and equipment $B$ is $0.71 \mathrm{~h} /$ year. In the annual direct loss of power outage of substation, equipment $\mathrm{A}$ is 42.84 thousand $\mathrm{kWh}$, and equipment $\mathrm{B}$ is 54.32 thousand $\mathrm{kWh}$. For the supply cost of the comprehensive load, it is calculated 10 times the average price, and the penalty price takes 5 yuan / $\mathrm{kWh}$ for the calculation. The outage cost of equipment per year for equipment $\mathrm{A}$ is 214.1 thousand yuan, equipment B is 271.6 thousand yuan. In the 30 year's life cycle, the equipment A outage cost is 6.426 million yuan, and the equipment $\mathrm{B}$ is 8.148 million yuan.

(4) decommissioning disposal cost DC analysis

The residual value of the transformer after 30 is calculated by $3 \%$, the residual value of the equipment $\mathrm{A}$ is 396.6 thousand yuan, and the equipment B is 384.6 thousand yuan. The cost structure of equipment A and B is shown in table 2 . 
TABLE 2. Cost reduction comparison of equipment A and B

\begin{tabular}{cccc}
\hline Items & $\begin{array}{c}\text { Equipment A (ten } \\
\text { thousand) }\end{array}$ & $\begin{array}{c}\text { Equipment B (ten } \\
\text { thousand) }\end{array}$ & $\begin{array}{c}\text { Difference between equipment A and } \\
\text { equipment B (ten thousand yuan) }\end{array}$ \\
\hline Investment cost & 1322 & 1282 & 40 \\
Running cost & 3620.8 & 4034.7 & -413.9 \\
Operation cost & 874177 & 2776.5 & -93.9 \\
Maintenance cost & 295.6 & 443.3 & -147.8 \\
Failure cost & 642.6 & 814.8 & -172.2 \\
Decommissioning & -39.66 & -38.46 & -1.2 \\
disposal cost & & & -375.1 \\
LCC static value & 4903.14 & 5278.24 & -167.88 \\
Present value of LCC & 2722.41 & 2890.29 & \\
\hline
\end{tabular}

Notice: discount rate $\mathrm{i}_{0}$ takes $7.5 \%$.

As can be seen from table 2, although the purchase cost of equipment $\mathrm{A}$ is higher than that of equipment $\mathrm{B}$, the operation and maintenance cost and failure cost of equipment $\mathrm{A}$ are lower than those of equipment B. Therefore, in the case that technical requirements are met, from the economic point of view, the main transformer should choose equipment A (Pillai, et al., 2016). When the parameters of the selected equipment are known, according to the analysis of fees produced in the life cycle by equipment cost model, we select the major fee factors that have great impact on the cost fee for the comparison, which can greatly simplify the calculation process. For instance, in the above analysis, we only select the parameters that have a greater impact on the equipment performance, fees having little difference with the installation costs, land cost and so on costs are omitted, while we can still get the analysis results.

\section{CONCLUSION}

This paper focuses on the application of the whole life cycle cost theory in the selection of main transformers and the selection of substation equipment maintenance strategies. In the selection method of main transformer based on life cycle cost theory, firstly, how to obtain the economic load rate with consideration of cost recovery of main transformer is analyzed, and then based on this, the scheme for selection of number and capacity of the main transformer is put forward, the whole life cycle cost for each program is evaluated, and the optimal cost scheme is selected. Finally, the cost structure and estimation model of the whole life cycle of the main transformer are analysed. The selection method of main transformer based on life cycle cost theory is put forward. This method is, based on the consideration of cost recovery of main transformer economic load rate, to put forward the selection process of the number and capacity of the main transformer. Therefore, it not only greatly simplifies the main transformer selection process, but also ensures the equipment running reliability and economy.

This work was financially supported by xxx fund.

\section{REFERENCES}

1. Wei, Y.. Application of device design life prediction method in life-cycle cost (lcc) evaluation of the substation automation system bidding. Electrical Engineering.

2. Hinow, M., \& Mevissen, M. Substation maintenance strategy adaptation for life-cycle cost reduction using genetic algorithm. IEEE Transactions on Power Delivery, 26(1), 197-204.

3. Wong, T. S., Lopezroldan, J., \& Saha, T. Development of a life cycle cost estimating tool to compare gis and ais substation projects. 1-5.

4. Liu, Y. Research and application on the technology system of plug \& play in the smart substation's life cycle. Power System Protection \& Control.

5. Suo, X., Hou, C., Sun, L., \& Liu, Z. 3D Reconstruction Optimization Algorithm Based on Dynamic Clustering in Transformer Substation. Journal of Computational and Theoretical Nanoscience, 14(1), 248-251.

6. Zhang, Y., \& Wang, P. Evaluation Analysis of Transformer Substation Radiation on Surrounding Environment. DEStech Transactions on Engineering and Technology Research, (iceta).

7. Pillai, R., Havaldar, F. N., Chunduru, S., \& Adkar, V. Substation Asset Performance, Residual Life, Health and Condition Metrics: Retrofilling Distribution Transformers With Natural Esters-Tata Power Experience. CIGRE India Journal, 5(2), 34-38. 